LITERATURE REVIEW

\title{
Literature review on maturity models for digital supply chains* $^{*}$
}

Frauke Hellweg ${ }^{1}$, Sandra Lechtenberg ${ }^{1}$, Bernd Hellingrath¹, Antonio Márcio Tavares Thomé2

${ }^{1}$ University of Münster, Münster, Germany.

${ }^{2}$ Pontifical Catholic University of Rio de Janeiro, Rio de Janeiro, RJ, Brazil.

How to cite: Hellweg, F., Lechtenberg, S. and Hellingrath, B. et al. (2021), “Literature Review on Maturity Models for Digital Supply Chains", Brazilian Journal of Operations \& Production Management, Vol. 18, No. 03, e20211127. https://doi.org/10.14488/BJOPM.2021.022

\section{ABSTRACT}

Goal: Today, digital technologies have significant effects on supply chains as companies explore and exploit their opportunities. Digital supply chains promise advantages over traditional ones. A maturity model is a helpful tool to assess the current state of digitalization in supply chains and to guide companies towards implementation. The main goal of this paper is to investigate existing maturity models for digital supply chains and propose possibilities for future research.

Design / Methodology / Approach: A structured literature review is conducted to identify relevant maturity models. Those are analyzed regarding their type and emphasis on a specific supply chain function or certain digitalization dimension.

Results: Twenty-eight maturity models are identified. Each of them focuses on a particular supply chain function or a specific digital technology. A focus on manufacturing (Industry 4.0) and, consequently, a lack of research regarding other aspects of the supply chain digitalization becomes evident. Moreover, most papers lack coverage of all digitalization dimensions. Besides, more rigorous research regarding the quality of the maturity models, their evaluation, and application is needed.

Limitations of the investigation: The conducted review is limited to two databases (Scopus and Web of Science). Two researchers conducted the analysis, which might lead to some bias. Furthermore, the analysis could be broadened and performed more in-depth to derive further insights.

Practical implications: Practitioners might use the presented overview of existing maturity models to identify a well-developed one that fits their desired application scenario.

Originality / Value: This paper provides suggestions for future research and highlights interesting and relevant topics to investigate.

Keywords. Digitalization; Supply Chain; Maturity Models; Literature Review

\section{INTRODUCTION}

Digital technologies are indispensable in today's society, having significant effects on companies and their businesses. Terms like smart manufacturing or big data are omnipresent, and companies make great effort to discover emerging technologies and benefit from them

*This article is from the XXVI International Conference on Industrial Engineering and Operations Management (IJCIEOM) and was invited to be published in the September/2021 Special Issue of the Brazilian Journal of Operations \& Production Management, due to its relevance and contribution to the field.

Financial support: None.

Conflict of interest: The authors have no conflict of interest to declare.

Corresponding author: frauke.hellweg@wi.uni-muenster.de

Received: 15 Dec 2020.

Approved: 15 Dec 2020.

Editor: Rafael Garcia Barbastefano. 
(Iddris, 2018). Supply Chain Management (SCM) is no exception. Some benefits of digital Supply Chains (SC) are increased visibility, higher flexibility due to real-time information, and ensuring customer responsiveness (Büyüközkan and Göçer, 2018). The benefits are attributed to the use of emerging technologies that turn traditional SC into digital SC (Iddris, 2018). Kersten et al. (2017) conducted an online survey with over 350 respondents from German manufacturing, logistics, trade, and consultancy companies. Seventy-three percent of the participants stated that the opportunities of digital transformation are very high for their company.

Academics and practitioners alike could benefit from roadmaps towards SC digitalization. Maturity Models (MM) can serve as a starting point for the digitalization process (Pullen, 2007). In an organizational context, the term maturity can be defined "as the degree to which a process is defined, managed, measured, and continuously improved" (Dooley et al., 2001: 23). MM are helpful tools and provide frameworks to determine the direction as well as priorities for further action. Despite the existence of many MM examining limited areas of SCM or specific digital technologies and even some first approaches to develop a MM for the digitalization of an entire SC, there is no consensus about how such a MM should look like (Reis et al., 2018). This lack of MMs considering the whole digital SC highlights the general lack of guidelines and structured approaches to help companies master the digital transformation by aligning traditional strategies with digital ones (Matt et al., 2015). One consequence of lacking guidance is that the potential of digital SC is not yet fully exploited and sufficiently demonstrated with empirical data in real-world situations (Büyüközkan and Göçer, 2018; Iddris, 2018).

In order to address this gap, this paper aims at a first step towards ultimately proposing a maturity model for digital SCM. This first step encompasses considering MM focusing only on parts of an SC, specific technologies, or aspects of digitalization to derive insights. The gained insights can form a basis towork towards a MM for the whole digital supply chain. To the best of our knowledge, currently, no study compares and analyzes MM in the field of digital supply chains. However, this should be the first step to contribute to addressing the research gap mentioned above, which then can be further addressed in future studies building upon the results of this paper. Consequently, the main goal of this paper is to identify MM considering at least parts of a digital SC in the literature, analyze them, and propose possibilities for future research. The following three research questions are derived:

1. Which relevant MM are there for evaluation whole or specific aspects of digital SC in the current body of literature?

2. On which specific parts of the SC or dimensions of digitalization do the identified $\mathrm{MM}$ focus?

3. What are the insights derived from the analysis regarding further research?

The remainder of the paper is structured as follows. First, a brief theoretical background for digital SC, as well as MM, is given. Section 3 presents the methodology of the literature review based on Thomé et al. (2016). The identified MM are analyzed in section 4. Further research directions derived from the insights of the literature review are presented in section 5. The paper closes with a summary of the results.

\section{THEORETICAL BACKGROUND}

This chapter presents the basic terms and definitions relevant to this study. The establishment of a common knowledge base, especially in regard to broad terms like "digitalization", is beneficial. Furthermore, four key dimensions of digitalization in supply chains are introduced that are referred to in the analysis chapter. Afterward, the main building blocks of MM and different types of MM are briefly presented. The proposed type distinction is applied in the analysis chapter. 


\section{Digital Supply Chains}

For talking about digital SC, the differentiation between "digitization" and "digitalization" is essential. While "digitization" simply refers to converting information from analog to digital, the latter describes the change of processes within organizations and possibly complete business models by "adopting and using digital technologies in broader individual, organizational, and societal contexts" (Legner et al., 2017: 301). However, unsurprisingly, the technological aspect gets a large share of the attention, as new technologies (e.g., EDI or ERP) started the digital transformation in the first place (Reis et al., 2018). As pointed out, the impacts of digitalization are enormous in all industries, including SCM. New terms like "digital supply chains" evolve, which are also often labeled as "smart", "intelligent", or with the suffix "4.0" (Shukla et al., 2018). Emerging technologies such as the Internet of Things, Artificial Intelligence, Cloud Computing, and Big Data Analytics are of high relevance for and inextricably linked to digital businesses (Büyüközkan and Göçer, 2018). The interplay of different technologies and their embedding into organizations is what creates value and new opportunities. The concept of "Industry $4.0^{\prime \prime}$ is an example of how this could be achieved (Shukla et al., 2018).

So far, no uniformly accepted definition of digital SC exists. Based on the above-described characteristics of a digital SC and Büyüközkan and Göçer (2018) and Raab and Griffin-Cryan (2011), we propose the following working definition: A digital supply chain is a value-driven network that utilizes digital technologies extensively to improve and also create new forms of revenue and business value for organizations. Based on this working definition and literature about the aspects of digital SC, we propose four dimensions of digitalization. First, the utilization of technologies, i.e., the technological digitalization is of high importance. Digitalization also affects processes, which are automated, and requires new methods such as supply chain analytics. Therefore, process \& method digitalization needs to be achieved. By improving and creating new forms of revenue and business value, business digitalization is aimed for. To achieve this, organizational digitalization is necessary, i.e., the transformation of organizational culture to accept and embed digitalization (Berghaus and Back, 2016; Büyüközkan and Göçer, 2018; Legner et al., 2017; Matt et al., 2015; Urbach and Röglinger, 2018).

\section{Maturity Models}

Generally speaking, the term "maturity" describes the highest state of development and "ripeness" of something (Cambrigde Dictionary). In the following, we are using a working definition based on Ahlemann et al., 2005. A maturity model defines different levels of maturity in order to be able to assess the extent to which an object (an organization, a process etc.) fulfills the defined requirements.

The description of each maturity level expresses when a certain level is reached. While the number of levels can differ between different MM, the lowest level always represents the most immature state, and the highest level represents the fully-grown and completely developed state, usually paradigmatic (Klimko, 2001). Dimensions depict different aspects of maturity and are derived from the application area. Sub-dimensions give a more granular view. Every sub-dimension should contain a detailed description of each maturity level. The above-described building blocks comply with components defined by Fraser et al. (2002) that are widely accepted as the basis for MM. Fraser et al. (2002) furthermore propose a typology for MM. First, maturity grids describe the activities necessary for each level (usually in text format). Second, in Likert-like questionnaires, the respondents have to rate the performance of the organization for different dimensions to assess maturity. A combination of the answers with descriptions of maturity results in hybrids. Lastly, Capability MM are more complex as they define goals and key practices for different process areas. In this paper, this typology is adapted, and the following four types of MM are differentiated:

- Grids: All levels and dimensions are presented, including every combination and its main characteristics, usually in spreadsheet format with descriptive text. 
- Assessment: The focus of the MM is on the assessment of the maturity level, and the method most frequently used are questionnaires. Questions are answered using scales or checklists and based on the given answers, one overall or separate maturity levels are calculated.

- Dimensions: The dimensions (and possibly sub-dimensions) are named and explained. No explicit requirements or connections to a certain maturity level exist.

- Levels: The levels or stages of maturity are identified and described but not directly linked to dimensions or measurement criteria.

Practitioners, as well as academics, have recognized the potential of MM. Hence, a large number of MM for different application areas have been created (Netland et al., 2007).

\section{METHODOLOGY}

A structured literature review (SLR) following the guidelines provided by Thomé et al. (2016) is performed to answer the first research question. The aim is to give an overview of the existing MM for digital SC.

Before elaborating on the procedure followed for the SLR, the overall research methodology of this paper is briefly classified according to the basic types of research proposed by Kothari and Garg (2019). This helps to get a better understanding not only of the research process, but it also allows for a more reliable interpretation of the results.

Regarding the time frame of the research, it can be stated that this study is a one-time research as the results are limited to a certain time frame. In this case, all literature until the beginning of 2020 is taken into consideration. The approach is mainly qualitative, as the performed literature review identifies MM and sorts them into functions along the supply chain, dimensions of digitalization, and evaluates the quality of the methodology. Most of the results are based on this qualitative procedure. However, some quantitative aspects are included as well, e.g., referring to the number of MM that discuss a certain dimension. These are included in the discussion and insight generation, but the quantitative analysis of papers is only elementary and can be enhanced.

Furthermore, the study can be classified into applied research, also called action research, and can be considered as conceptual, descriptive research (Kothari and Garg, 2019). The paper aims at structuring and describing the body of literature regarding a certain practical problem identified, i.e., it wants to perform a first step towards developing a MM that can help companies to transform their SC to digital ones.

Literature reviews are a suitable research method to achieve this goal; however, they should be conducted following a structured approach to ensure rigor and traceability. Hence, Thomé et al. (2016) propose an eight-step approach, which is applied. First, the problem needs to be planned and formulated, which was reported in the introduction. An initial scoping review has been conducted to get a basic understanding of the field. Section 2 elaborates on the necessary terms and provides definitions. The topic of digital MM in SC targets multiple disciplines. Consequently, it is unreasonable to focus on area-specific journals. Two databases, Scopus and Web of Science (WoS), are chosen to cover interdisciplinary literature from different types of sources and disciplines. The following search string has been applied: ((digit* OR smart OR intellig* OR 4.0) AND ("supply chain*" OR "value chain*" OR logistic*) AND maturity). The search term consists of three parts: part one ensures results dealing with digitalization, while part two warrants results from the field of SCM, and part three reduces the search to sources coping with any form of maturity (models). It is searched in the title, keywords, and abstracts. Results are limited to English, with no time restriction. The search string resulted in 174 papers from the two databases. Duplicates were removed manually. Furthermore, the search is completed with 44 additional articles from forward and backward search based on key publications identified as well as ones identified in the scoping review used to define terms and keywords. This amounts to 183 papers in total, and at least two authors have checked their titles and abstracts to verify their relevance. Papers are excluded if both reviewers agreed that they fulfill at least one of the following exclusion criteria: 
- Domain different from SCM: Some papers dealt with other domains than SCM, e.g., medicine or biology. Often they appeared in the results as they applied the method "logistic regression" and hence fulfilled the second part of the search term.

- No focus on digitalization: In very few cases, papers proposed a MM for an aspect of SCM but did not cover any aspects of digital supply chains. Instead, digitalization was often mentioned as a future research possibility.

- Not proposing a maturity model: As only "maturity" was part of the search term also to cover sources discussing maturity assessments, many results did not include a model but the term maturity in a different context (e.g., maturity of fruits).

The two reviewers have agreed in $96.5 \%$ of the cases, and Krippendorff's Alpha was 0.884 , allowing the conclusion that the exclusion criteria were well-understood by both reviewers and that the selection had high reliability. Results of Krippendorf's alpha above 0.8 indicate an acceptable level of agreement in confirmatory research (Krippendorf, 2020).

After reviewing the abstracts, a full-text review of 42 articles has led to the exclusion of an additional 14 sources. In sum, the initial scoping review and the structured database search has led to 28 relevant papers. Figure 1 depicts the process of the conducted literature review using the PRISMA Flow Diagram (Moher et al., 2009).

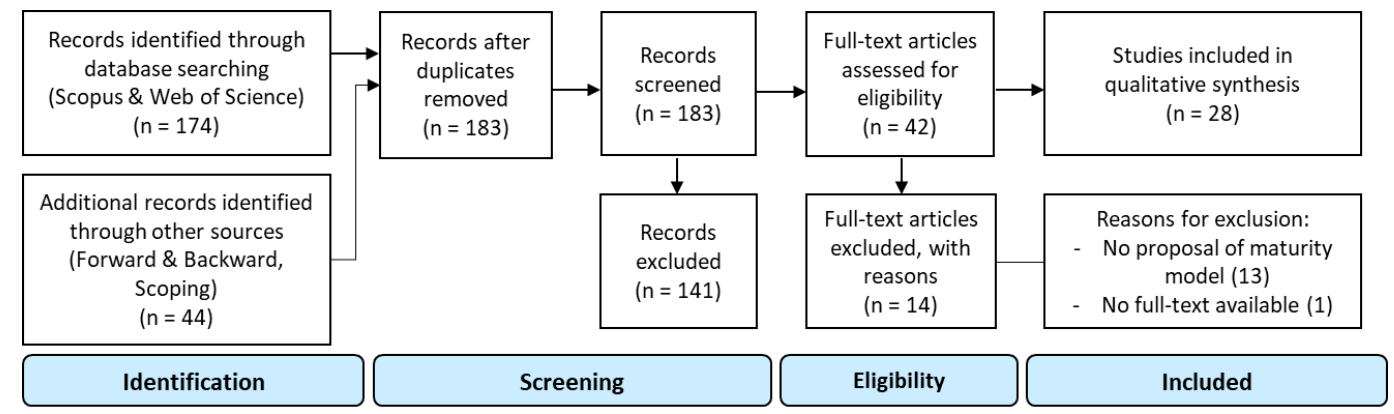

Figure 1. The PRISMA Flow Diagram of the Conducted Literature Review. Source: Designed from Moher et al. (2009)

\section{RESULT AND EVALUATION OF THE LITERATURE REVIEW}

Taking into account the 28 papers identified, the number of publications increases from the year 2014 onwards until 2018 (see Figure 2; only the completed years are taken into account). However, the increase is not steady, and in the years 2015, 2017, and 2019 a slight decrease is identified. This might be caused by the limited selection of 28 papers. Nonetheless, the general trend of an increasing amount of publications is an indicator of the growing attention in this emerging field of research. We also noticed that the first publications on the subject are as recent as 2014.

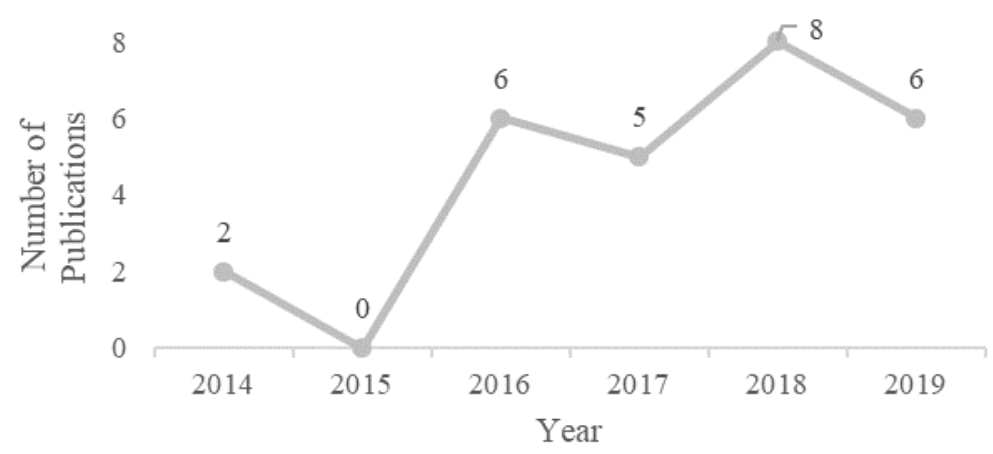

Figure 2. Development of Number of Publications per Year. Source: The authors themselves 
To shed some light on the relevance of the research topic, the authors of this paper investigate the number of citations of the identified literature. Not all identified papers are included in Scpous or Web of Science, respectively. Therefore, a uniform database for comparing the number of citations is used, namely Google Scholar. The relevant information is determined in February 2020, and the authors want to point out that the numbers are subject to change over time as they are dynamic. The number of citations, with an average of 46 citations per paper at this point of time, confirms the presumed relevance of the research topic. One paper has been cited as often as 381 times (Schumacher et al., 2016). Authors citing MM aim at developing their own model, at comparing existing MM but mostly at applying existing MM to specific cases.

The interest both from scientific as well as industry side is reflected when looking at the type of publications. While the majority of papers are published in conference proceedings (10), journal publications (10), or books (3), some models stem from industry-related grey literature (5). The expression "grey literature" refers to articles that are not published by commercial publishers but are e.g., government reports, technical notes, or issue papers. In this study, most grey literature stems from consultancy companies (4) and one national academy.

The majority of the examined MM are grids (13). One reason for their frequent use is the detailed representation of dimensions and characteristics for each level.

This allows the assessment of maturity levels for each dimension separately and therefore gives a differentiated overview. The remaining MM are equally divided among the other three types, namely assessment (4), dimensions (5), and levels (6). They are not as extensively used as grids. Assessments are often applied to specific case studies, and the outcome is evaluated (Blatz et al., 2018). The degree of detail regarding the specific questionnaire presented, used calculation methods and software tools for the application of the assessment varies. Only one paper presented the calculation, as well as the software used in detail (Gaur and Ramakrishnan, 2019). The third type of MM is the one presenting different (sub-) dimensions. They focus on how to structure the topic of digitalization of SC and develop dimensions on this basis. The models of the type level are quite general and provide an overview of the general direction of a company's digitalization efforts. They mostly remain rather vague in their descriptions. For example, Gustafsson et al. (2019) only use a few sentences to describe the proposed levels of maturity. An explanation for this can be that most papers are the first draft and at a preliminary stage of research and not yet completely elaborated (Ellefsen et al., 2019).

To answer the second research question posed in the introduction chapter of this study, the papers were analyzed according to whether they limit the application area of their model to a specific function of SC. Functions are defined as plan, source, make, deliver, and return according to the Supply Chain Operations Reference (SCOR)-model (Stölzle and Halsband, 2005). Moreover, it was examined which of the digitalization dimensions proposed in section 2 are addressed. Indeed, the majority focused on a specific SC function or limited the number of discussed digitalization dimensions (see Table 1). The final column assesses the extent of the description regarding the methodological and theoretical foundation of the development process. Papers often miss the sound theoretical basis and description of the development process of the models (Blatz et al., 2018; de Carolis et al., 2017). This results in a lack of transparency and is a major point for criticism. In our research, it can also be observed that the majority of examined models either state no description at all (11) or provide only a basic and incomplete description (12). Only five models describe the methodology used in detail and show the application process utilizing the developed model. Two papers applied the approach by de Bruin et al. (2005) in the model developemnt (Asdecker and Felch, 2018; de Carolis et al., 2017). The most recent paper uses the process model by Becker et al. (2009) as a basis (Hausladen and Schosser, 2020). The two other papers depicted the development process in detail but refered to no specific MM development process but borrowed from 
neighbouring areas, e.g. case study research (Arunachalam et al., 2018; Mendes Junior et al., 2016).

Table 1. Overview of relevant maturity models and their focus.

\begin{tabular}{|c|c|c|c|c|c|c|}
\hline \multirow[b]{2}{*}{ Author (Year) } & \multirow[b]{2}{*}{$\begin{array}{c}\text { SC } \\
\text { Function }\end{array}$} & \multicolumn{4}{|c|}{ Dimensions of Digitalization } & \multirow[b]{2}{*}{$\begin{array}{l}\text { Metho- } \\
\text { dology }\end{array}$} \\
\hline & & $\begin{array}{l}\text { Busi- } \\
\text { ness }\end{array}$ & $\begin{array}{l}\text { Organi- } \\
\text { zational }\end{array}$ & $\begin{array}{l}\text { Process } \\
\& \\
\text { Method }\end{array}$ & $\begin{array}{l}\text { Techno- } \\
\text { logical }\end{array}$ & \\
\hline Aimi et al. (2017) & Deliver & & $x$ & $x$ & $x$ & 1 \\
\hline Akdil et al. (2018) & General & $x$ & & $x$ & $x$ & 2 \\
\hline Anderson and Ellerby (2018) & General & $x$ & $x$ & & $x$ & 1 \\
\hline Arunachalam et al. (2018) & General & & $x$ & & $x$ & 3 \\
\hline Asdecker and Felch (2018) & $\begin{array}{l}\text { Source, } \\
\text { Deliver }\end{array}$ & & & $x$ & $x$ & 3 \\
\hline Barata and Cunha (2017) & Make & & & $x$ & $x$ & 2 \\
\hline Bibby and Dehe (2018) & Make & $x$ & $x$ & & & 2 \\
\hline Blatz et al. (2018) & General & $x$ & $x$ & $x$ & $x$ & 2 \\
\hline de Carolis et al. (2017) & Make & & $x$ & $x$ & $x$ & 3 \\
\hline Ellefsen et al. (2019) & $\begin{array}{l}\text { Make, } \\
\text { Deliver }\end{array}$ & $x$ & & $x$ & $x$ & 1 \\
\hline Frederico et al. (2019) & General & & $x$ & & $x$ & 2 \\
\hline Ganzarain and Errasti (2016) & Make & $x$ & & & & 1 \\
\hline Gaur and Ramakrishnan (2019) & Make & $x$ & & $x$ & $x$ & 2 \\
\hline Geissbauer et al. (2016) & General & $x$ & & & $x$ & 1 \\
\hline Gustafsson et al. (2019) & General & & & & $x$ & 2 \\
\hline Hausladen and Schosser (2020) & Plan & $x$ & $x$ & & $x$ & 3 \\
\hline Issa et al. (2018) & General & $x$ & & & & 1 \\
\hline Klötzer and Pflaum (2016) & Make & $x$ & $x$ & $x$ & $x$ & 2 \\
\hline Krowas and Riedel (2019) & Make & & $x$ & $x$ & $x$ & 2 \\
\hline Leyh et al. (2016) & General & & & & $x$ & 1 \\
\hline Mendes Junior et al. (2016) & General & $x$ & & $x$ & $x$ & 3 \\
\hline $\begin{array}{l}\text { Oleśków-Szłapka and } \\
\text { Stachowiak (2018) }\end{array}$ & $\begin{array}{l}\text { Source, } \\
\text { Deliver }\end{array}$ & & & & $x$ & 1 \\
\hline Schuh et al. (2017) & Make & & $x$ & & $x$ & 2 \\
\hline Schumacher et al. (2016) & Make & $x$ & $x$ & & $x$ & 2 \\
\hline Solis (2017) & General & $x$ & & & & 1 \\
\hline Uhl and Gollenia (2014) & General & $x$ & $x$ & & & 1 \\
\hline Wang et al. (2018) & Make & $x$ & & $x$ & $x$ & 1 \\
\hline Weber et al. (2017) & Make & & & $x$ & $x$ & 2 \\
\hline
\end{tabular}

Source: The authors themselves.

1: No / 2: Basic / 3: Detailed description of the theoretical and methodological basis for the development process of the maturity model

The function of the SC most commonly focused on is "make". Eleven papers solely consider the digitalization of this function. For example, they only discuss digitalization within the production of one company but do not address connections to customers and/or suppliers. Only four papers deal with source and/or delivery functions. They do not explicitly mention a focus on sourcing or delivering but rather propose MM for general logistics processes of companies. While at least one paper examines the planning function, no source deals with return functions. 
The focus on manufacturing is also mirrored by the fact that over $50 \%$ of the identified MM specialized in the area of "Industry 4.0". Two papers focus on Big Data Analytics (Arunachalam et al., 2018; Hausladen and Schosser, 2020), one on Artificial Intelligence (Ellefsen et al., 2019) and one on Internet of Things (Ellefsen et al., 2019).

The analysis of the different digitalization dimensions supports the impression that existing MM focus on the technological aspects of digitalization. The technological dimension is addressed by more than $80 \%$ of the models. However, all other dimensions are only considered by about half of the models. Indeed, there are only two models including all dimensions of digitalization, namely Blatz et al. (2018) as well as Klötzer and Pflaum (2016). However, both limit the applicability of their model. Blatz et al. focus on small and medium enterprises, and Klötzer and Pflaum present a model specifically for manufacturing.

So while there are a few models either considering the entire SC or addressing all dimensions of digitalization or presenting a detailed description of levels and dimensions, there is no model combining all of those aspects. Furthermore, the rigor of the development process description is improvable for most MM. This supports the assumption that this field of research already provides interesting initial insights but that many future research possibilities are still to be worked upon.

\section{FUTURE RESEARCH}

The presented results are based on an initial appraisal and analysis of the identified MM. There is a multitude of further possibilities to study the models, compare them, and get insights regarding their quality and value for the industry. A first approach was to examine if the development process was documented and theoretically founded. Future research should examine if the criteria for the development of MM proposed by Becker et al. (2009) are applied. By identifying high-quality models, it can be assured that further research only considers those and insights are based on rigorous research. Moreover, the identified models can be compared based on other critera and analyzed more in-depth, e.g., their specific dimensions. It is important to point out that this study only includes papers published until the beginning of 2020. Therefore, subsequent research should supplement the findings with the latest results from research and update the study.

Moreover, the literature search should be extended to identify further MM. More specific searches might lead to MM focusing on technologies such as big data analytics or artificial intelligence, on other dimensions of digitalization or on functions of the SC currently not sufficiently addressed (such as plan or return). Besides, there might be MM for digital transformation not focusing on SC that could still provide valuable insights. Due to the search term and exclusion criteria, these could not be identified so far. Another valuable starting point to identify further MM is the inclusion of other databases. Currently, only Scopus and Web of Science are used. However, this can be enhanced in future studies.

Looking at what the identified sources propose as future research, it becomes evident that the application of $\mathrm{MM}$ is an appealing topic. So far, developed models have not sufficiently been validated by applying them to different companies and ideally to different industries. Bruin et al. present different purposes of MM in their work, namely, descriptive, prescriptive, or comparative (de Bruin et al., 2005). The application of a comparative model might lead to interesting cross-industry comparisons. While some models focus on a specific industry, many others do not consider all dimensions of digitalization. Hence, the development of a MM that is not only applicable to the entire SC independently from an industry but also includes the four dimensions of digitalization is proposed as a future research possibility.

While the identified MM try to give an assessment of how digital a SC is at its current state, no suggestions on how to improve, i.e., how to move to the next maturity level, are proposed. Hence, the creation of a roadmap for digitalization within a company is of high interest. The identification of triggers moving between levels and recommendation of steps for improvement are necessary and has not been addressed by the identified papers. 
Furthermore, considerations about the required capabilities of an organization to reach a given maturity level are currently missing.

\section{CONCLUSION}

This paper presented the first results of a structured literature review regarding MM for digital SC. To our knowledge, no similar literature review, focusing on the identification of MM in this field of research and comparing them, exists. Twenty-eight papers, each proposing a $\mathrm{MM}$, were identified as a result of the first research question. Afterward, the MM were examined with regard to the type of model they propose as well as to whether they focus on a specific aspect of the supply chain or digitalization, and the foundation of the development process. The insights build the basis for answering the second research question posed in the introduction chapter of this paper. Due to the high number of citations and because relevant papers stem both from science and industry, it becomes clear that there is a high interest in the topic in general. However, most of the models focus on the technological dimension of digitalization and/or on one part of the supply chain, such as the "make" function. Moreover, there is a clear lack of practical evaluation of these models. Only a few sources apply their model to a real-case, and often it is stated that it is questionable whether a model can be applied to more than one industry. Based on the presented first analysis, future research options have been proposed. They revolve around further checking the quality of papers, identifying more $\mathrm{MM}$, and developing a roadmap to give guidance on how to achieve the next level of digitalization. This answers the final research question of this paper.

The main theoretical contribution is the structured representation of identified MM in the current body of literature regarding digital supply chains. This helps to build the foundation for further research in this area and create a common knowledge base. The proposal of future research possibilities can serve as an indication of where to go next and which aspects to address to ultimately develop a MM considering the whole SC and all dimensions of digitalisation. As a practical contribution, practitioners can use MM as a starting point for digitalization endeavors of their companies' supply chains. Therefore, the overview of identified MM might be supportive to identify a well-developed MM that fits their desired application scenario.

However, certain limitations regarding this study have to be pointed out. First, literature reviews are often subject to restrictive decisions made by the authors. In this case, the decision to include only the two databases Scopus and Web of Science is a limitation. Including further databases might result in different results. In addition, only two researchers read the abstracts and accomplished the full-text review. The reliability of this research would increase with additional researchers. Second, the analysis of the identified MM based on selected areas, e.g., the supply chain areas (structured according to the SCOR model) and the digitalization dimensions. This is only one possible solution to approach the analysis and is not exhaustive. As stated in the future research chapter, also a critical examination regarding the quality of the developed MM would be beneficial. Overall, it can be subsumed that in the field of MM for digital SC many questions remain unanswered. Various options for future research to contribute to the field exist.

\section{REFERENCES}

Ahlemann, F., Schroeder, C. and Teuteberg, F. (2005), Kompetenz- und Reifegradmodelle für das Projektmanagement: Grundlagen, Vergleich und Einsatz. Universität FB Wirtschaftswiss Organisation u Wirtschaftsinformatik, Osnabrück.

Aimi, G., Lisica, J. and Gonzalez, D. (2017), Apply the Five-stage maturity model to drive logistics excellence within the supply chain, Stamford, Gartner.

Akdil, K.Y., Ustundag, A. and Cevikcan, E. (2018), "Maturity and readiness model for industry 4.0 strategy", in Ustundag, A and Cevikcan, E (Eds.), Industry 4.0: Managing the digital transformation, Springer, Cham, pp. 61-94. http://dx.doi.org/10.1007/978-3-319-57870-5_4. 
Anderson C and Ellerby W (2018), Digital maturity model: achieving digital maturity to drive growth, Deloitte Development ULC, OSA. Online at: https://www2.deloitte.com/content/dam/Deloitte/global/Documents/Technology-MediaTelecommunications/deloitte-digital-maturity-model.pdf

Arunachalam, D., Kumar, N. and Kawalek, J.P. (2018), "Understanding big data analytics capabilities in supply chain management: Unravelling the issues, challenges and implications for practice", Transportation Research Part E, Logistics and Transportation Review, Vol. 114, pp. 416-36. http://dx.doi.org/10.1016/j.tre.2017.04.001.

Asdecker, B. and Felch, V. (2018), "Development of an Industry 4.0 maturity model for the delivery process in supply chains", Journal of Modelling in Management, Vol. 13, No. 4, pp. 840-83. http://dx.doi.org/10.1108/JM2-03-2018-0042.

Barata, J. and Cunha, P. (2017), "Climbing the maturity ladder in Industry 4.0: A framework for diagnosis and action that combines national and sectorial strategies", in 23rd Americas Conference on Information Systems (AMCIS), Boston, USA.

Becker, J., Knackstedt, R. and Pöppelbuß, J. (2009), "Developing Maturity Models for IT Management", Business \& Information Systems Engineering, Vol. 1, No. 3, pp. 213-22. http://dx.doi.org/10.1007/s12599-009-0044-5.

Berghaus, S. and Back, A. (2016), "Gestaltungsbereiche der digitalen transformation von unternehmen: Entwicklung eines Reifegradmodells", Die Unternehmung, Vol. 70, No. 2, pp. 98-123. http://dx.doi.org/10.5771/0042-059X-2016-2-98.

Bibby, L. and Dehe, B. (2018), "Defining and assessing industry 4.0 maturity levels - case of the defence sector", Production Planning and Control, Vol. 29, No. 12, pp. 1030-43. http://dx.doi.org/10.1080/09537287.2018.1503355.

Blatz, F., Bulander, R. and Dietel, M. (2018), "Maturity Model of Digitization for SMEs", in IEEE International Conference on Engineering, Technology and Innovation, IEEE, Piscataway, NJ, pp. 1-9.

de Bruin, T., Freeze, R., Kulkarni, U. et al. (Eds.) (2005), “Understanding the main phases of developing a maturity assessment model", in 16th Australasian Conference on Information Systems, Sydney, 29 Nov-2 Dec 2005.

Büyüközkan, G. and Göçer, F. (2018), "Digital Supply Chain: Literature review and a proposed framework for future research", Computers in Industry, Vol. 97, pp. 157-77. http://dx.doi.org/10.1016/j.compind.2018.02.010.

Cambridge Dictionary, C.D. (2019), "Maturity”, available at: https://dictionary.cambridge.org/de/worterbuch/ englisch/maturity (accessed 2 July 2019).

de Carolis, A., Macchi, M., Negri, E. et al. (2017), "A maturity model for assessing the digital readiness of manufacturing companies" in Lödding, H., Riedel, R., Thoben, K.-D., von Cieminski, G. and Kiritsis, D. (Eds.), Advances in production management systems, Springer, Cham, pp. 13-20. http://dx.doi.org/10.1007/978-3-319-66923-6_2.

Dooley, K., Subra, A. and Anderson, J. (2001), "Maturity and its impact on new product development project performance", Research in Engineering Design, Vol. 13, No. 1, pp. 23-9. http://dx.doi.org/10.1007/s001630100003.

Ellefsen, A.P.T., Oleśków-Szłapka, J., Pawłowski, G. et al. (2019), "Striving for excellence in ai implementation: Ai maturity model framework and preliminary research results", Logforum, Vol. 15, No. 3, pp. 363-76. http://dx.doi.org/10.17270/J.LOG.2019.354.

Fraser, P., Moultrie, J. and Gregory, M. (2002) The use of maturity models/grids as a tool in assessing product development capability. In: Managing technology for the new economy. Piscataway, NJ: IEEE Operations Center, pp. 244-249. http://dx.doi.org/10.1109/IEMC.2002.1038431.

Frederico, G.F., Garza-Reyes, J.A., Anosike, A., et al. (2019). Supply Chain 4.0: Concepts, maturity and research agenda. Supply Chain Management: An International Journal 25(2) 262-282.

Ganzarain, J. and Errasti, N. (2016), "Three stage maturity model in SME's toward industry 4.0", Journal of Industrial Engineering and Management, Vol. 9, No. 5, pp. 1119. http://dx.doi.org/10.3926/jiem.2073.

Gaur, L. and Ramakrishnan, R. (2019), "Developing internet of things maturity model for manufacturing," International Journal of Innovative Technology and Exploring Engineering, Vol. 9, No. 1, pp. 2473-2479.

Geissbauer, R., Vedso, J. and Schrauf, S. (2016), Industry 4.0: Building the digital enterprise, PwC, Munich. 
Gustafsson E, Jonsson P and Holmström J (2019) Digital product fitting in retail supply chains: maturity levels and potential outcomes. Supply Chain Management: An International Journal, ahead-of-print. http://dx.doi.org/10.1108/SCM-07-2018-0247.

Hausladen, I. and Schosser, M. (2020), "Towards a maturity model for big data analytics in airline network planning", Journal of Air Transport Management, Vol. 82, pp. 101721. http://dx.doi.org/10.1016/j.jairtraman.2019.101721.

Iddris, F. (2018), "Digital supply chain: survey of the literature", International Journal of Business Research and Management, Vol. 9, No. 1, pp. 47-61.

Issa, A., Hatiboglu, B., Bildstein, A. et al. (2018), "Industrie 4.0 roadmap: Framework for digital transformation based on the concepts of capability maturity and alignment", Procedia CIRP, Vol. 72, pp. 973-8. http://dx.doi.org/10.1016/j.procir.2018.03.151.

Kersten, W., Seiter, M., von See, B. et al. (2017), Trends und strategien in logistik und supply chain management: chancen der digitalen, DVV Media Group GmbH, Hamburg.

Klimko, G. (2001), "Knowledge management and maturity models: Building common understanding”, in Proceedings of the European Conference on Knowledge Management, ACPI, Southampton, pp. 269-278.

Klötzer, C. and Pflaum, A. (2016, "Toward the development of a maturity model for digitalization within the manufacturing industry's supply chain", in Proceedings of the $50^{\text {th }}$ Hawaii International Conference on System Science

Kothari, C.R. and Garg, G. (2019), Research methodology: Methods and techniques. New Delhi: New Age International (P) Limited Publishers.

Krippendorf, K. (2020), “Computing Krippendorff 's Alpha-Reliability", available at: https://repository.upenn.edu/asc_papers/43 (accessed 11 February 2020).

Krowas, K. and Riedel, R. (2019), "Planning Guideline and Maturity Model for Intra-logistics 4.0 in SME”, in Ameri, F., Stecke, K.E., von Cieminski, G. and Kiritsis, D. (Eds.), Advances in Production Management Systems. Towards Smart Production Management Systems, Springer International Publishing, Cham, pp. 331-338.

Legner, C., Eymann, T., Hess, T. et al. (2017), "Digitalization: Opportunity and challenge for the business and information systems engineering community", Business \& Information Systems Engineering, Vol. 59, No. 4, pp. 301-8. http://dx.doi.org/10.1007/s12599-017-0484-2.

Leyh, C., Schäffer, T., Bley, K. et al. (2016), “SIMMI 4.0 - A Maturity Model for Classifying the Enterprisewide IT and Software Landscape Focusing on Industry 4.0.", in Proceedings of the 2016 Federated Conference on Computer Science and Information Systems, IEEE, pp. 1297-302. http://dx.doi.org/10.15439/2016F478.

Matt, C., Hess, T. and Benlian, A. (2015), "Digital Transformation Strategies", Business \& Information Systems Engineering, Vol. 57, No. 5, pp. 339-43. http://dx.doi.org/10.1007/s12599-015-0401-5.

Mendes Junior, P., Leal, J.E. and Thomé, A.M.T. (2016), "A maturity model for demand-driven supply chains in the consumer product goods industry", International Journal of Production Economics, Vol. 179, pp. 153-65. http://dx.doi.org/10.1016/j.ijpe.2016.06.004.

Moher, D., Liberati, A., Tetzlaff, J. et al. (2009), "Preferred reporting items for systematic reviews and metaanalyses: the PRISMA statement", PLOS Medicine, Vol. 6, No. 7, pp. e1000097. http://dx.doi.org/10.1371/journal.pmed.1000097. PMid:19621072.

Netland, T.H., Alfnes, E. and Fauske, H. (2007), “How mature is your supply chain? A supply chain maturity assessment test", available at: https://www.sintef.no/globalassets/project/smartlog/publikasjoner/2007/netland-et-al-_2007_-howmature-is-your-supply-chain.pdf (accessed 11 February 2020).

Oleśków-Szłapka, J. and Stachowiak, A. (2018), “The Framework of Logistics 4.0 Maturity Model”, in Burduk, A (Ed.), Intelligent Systems in Production Engineering and Maintenance. Springer International Publishing, Cham, pp. 771-781.

Pullen, W. (2007), "A public sector HPT maturity model", Performance Improvement, Vol. 46, No. 4, pp. 9 15. http://dx.doi.org/10.1002/pfi.119.

Raab, M. and Griffin-Cryan, B. (2011), Digital Transformation of Supply Chains: Creating Value - When Digital Meets Physical. Capgemini Consulting. 
Reis, J., Amorim, M., Melão, N. et al. (2018), “Digital transformation: A literature review and guidelines for future research", in Rocha, Á., Adeli, H., Reis, L.P. and Costanzo, S. (Eds.), Trends and advances in information systems and technologies, Springer International Publishing, Cham, pp. 411-21. http://dx.doi.org/10.1007/978-3-319-77703-0_41.

Schuh, G., Anderl, R., Gausemeeier, J., et al. (2017), Industrie 4.0 Maturity Index: Managing the Digital Transformation of Companies, Utz, München.

Schumacher, A., Erol, S. and Sihn, W. (2016), "A maturity model for assessing industry 4.0 readiness and maturity of manufacturing enterprises", Procedia CIRP, Vol. 52, pp. 161-6. http://dx.doi.org/10.1016/j.procir.2016.07.040.

Shukla, S., Goel, G. and Vasudevan, A. (2018), "Building a digital supply chain the right way", available at: https://www.apics.org/apics-for-individuals/apics-magazine-home/magazine-detailpage/2018/01/04/building-a-digital-supply-chain (accessed 15 July 2019).

Solis, B. (2017), The six stages of digital transformation maturity, Altimeter Group, San Mateo, CA. Online available at: https://thedigitalminds.de/wp-content/uploads/2020/05/6-stages-of-DM-v4b.pdf

Stölzle, W. and Halsband E (2005), “Das Supply Chain Operations Reference (SCOR)-Modell”, Controlling, Vol. (8-9), pp. 541-543.

Thomé, A.M.T., Scavarda, L.F. and Scavarda, A.J. (2016), "Conducting systematic literature review in operations management", Production Planning and Control, Vol. 27, No. 5, pp. 408-20. http://dx.doi.org/10.1080/09537287.2015.1129464.

Uhl, A. and Gollenia, L.A. (2014), Digital enterprise transformation, Gower, Surrey, England.

Urbach, N. and Röglinger, M. (2018), Digitalization cases: how organizations rethink their business for the digital age. Springer International Publishing, Cham.

Wang, Y., Tran, T. and Anderl, R. (2018) Toolbox approach for the development of new business models in industrie 4.0. In: Proceedings of the World Congress on Engineering and Computer Science 2018

Weber, C., Königsberger, J., Kassner, L. et al. (2017), "M2DDM - A Maturity Model for Data-Driven Manufacturing", Procedia CIRP, Vol. 63, pp. 173-8. http://dx.doi.org/10.1016/j.procir.2017.03.309.

Author contributions: Frauke Hellweg and Sandra Lechtenberg had roughly the same amount of work. They were responsible for the data collection, analysis and writing of the article. Scientific supervision and continuous feedback for the whole paper was given by Bernd Hellingrath and Marcio Thomé. 